\title{
National innovation system capabilities among leader and follower countries: Widening gaps or global convergence?
}

\author{
Teemu Makkonen \\ Department of Border Region Studies, University of Southern Denmark, Sønderborg, Denmark \\ Address: Alsion 2, DK-6400 Sønderborg, Denmark \\ Telephone: +4565508302 \\ Fax: +456550 1779 \\ Email: teemu@sam.sdu.dk
}

The concept of technological catch-up, as it refers to a situation where some less developed countries have been able to catch up to the world leaders in terms of innovation, has inspired an abundant amount of scholarly attention. However, studies comprehensively focusing on factors considered important for innovation in the literature on national innovation systems (NISs) are rare. This gap is addressed here through a systematic analysis of the different dimension of NISs. Despite some positive signs, the global differences are growing i.e. the gaps between the best and the weakest performers are widening. Still, whereas on a global scale convergence is far from being the reality, the analysis was able to indicate a group of countries that have been able to catch-up to the "best in class" countries. Accordingly, there seems to be a clear association between NIS capabilities and the levels of economic development of countries.

Keywords: BRICS countries; economic development; national innovation system; principal component analysis; technological catch-up

This is an Accepted Manuscript of an article published by Taylor \& Francis Group in Innovation and Development on 18 Dec 2014, Vol. 5, No. 1, pp. 113-129. Available online: http://www.tandfonline.com/doi/abs/10.1080/2157930X.2014.992818 


\section{Introduction}

Economists, economic historians and economic geographers (among others) have for long been interested in the concept of "technological catch-up" as it refers to the ability of some formerly less developed countries to catch-up to the world leaders in economic terms (e.g. Abramovitz 1986; Gerschenkron 1962). Due to its complexity, the literature on catching-up has evolved in recent decades towards systemic approaches (Fagerberg and Srholec 2008). An important reference point in the contemporary debate on technological catch-up is, thus, the abundant literature (for a review see Fagerberg and Sapprasert [2011]) on "national innovation systems" (NISs). The reasoning behind this recent interest on NIS capabilities and technological catch-up has been aptly summarized by Castellacci and Archibugi $(2008,1670)$ :

"In a Schumpeterian perspective, innovative capabilities constitute a key engine of growth, and an important source of cumulativeness in the dynamics of economic systems. A greater innovation gap today is likely to lead to a greater income gap tomorrow. The interaction between technological and economic factors would thus possibly drive the countries further and further apart and such a Myrdalian cumulative causation could therefore lead to greater disparities in the years ahead".

However, only a few systematic empirical accounts in terms of technological catch-up vis-à-vis NISs exist. This gap is addressed here through an analysis of the different dimension of NISs, namely innovation and technological capabilities, human capital, infrastructures, economic competitiveness, political-institutional factors, and social capital with indicators from the CANA database (covering a time period from 1980 to 2008).

In conceptual terms there is a distinction to be made between catch-up and the more wide scale phenomenon of convergence: whereas catch-up, not to be confused with exact copying (Nelson 2004), refers to the experienced narrowing of the gap (to the global leaders) by an individual country, 
convergence relates to a situation where global overall differences would be shrinking (Fagerberg and Godinho 2004). However, it seems that this kind of global convergence is highly unlikely and, rather, at best one can describe a number of converging groups (or clubs) of countries (Castellacci and Archibugi 2008). This dichotomy acts as the motivation behind this paper: the issue of global convergence in the technological capabilities of countries is examined through different dimensions of NISs to investigate 1) whether or not there is evidence on the existence of contemporary global convergence in NIS capabilities, 2) whether one can designate clear groupings of converging (catching-up) countries, and 3) how do these results relate to economic development?

\section{National innovation systems: Definition, dimensions and technological catch-up}

\subsection{Varying definitions of national innovation systems}

Since the early works on NISs by Freeman (1987), Lundvall (1992), and Nelson (1993) the concept has evolved to encompass a number of varying definitions and has spurred a diversity of related concepts, such as regional, sectoral, and technological innovation systems. As a common nominator the varying definitions consider innovation through a systemic approach with feed-back loops rather than as a linear process. Similarly, in NIS definitions the importance of other actors than strictly firms engaged in innovative activities are stressed and brought to the fore when discussing the innovative capabilities and performances of nations.

Already in the 1980s, Perez (1983) discussed on a national level how structural changes and the assimilation of technological innovations are driven through two distinct groups (namely the "socioinstitutional" and "techno-economic" sub-systems) of characteristics. Accordingly, the concept of NISs can be defined in a narrow (the main sources of innovation, i.e. those institutions that are deliberately promoting the acquisition and dissemination of knowledge) and broad (a wider socioeconomic system including political and cultural determinants) sense (Freeman 2002; Lundvall 
1992). As stated by Lundvall (2011) narrow definitions of NISs are of limited relevance when it comes to the NISs of the less developed economies due to their modest innovative output (which does not necessarily coincide with contemporary and future potential for innovation). Thus, here the broad definition of NISs was adopted as the framework for the empirical investigation. At the same time, however, when considering NISs according to the broad definition, the empirical measurement of NISs becomes highly problematic, since the complexity of the approach renders quantitative analysis challenging (Katz 2006). Castellacci and Natera (2011) have proposed a division of six distinct dimensions to be considered when threating NISs empirically: 1) innovation and technological capabilities, 2) education system and human capital, 3) infrastructures, 4) economic competitiveness, 5) political-institutional factors, and 6) social capital. Thus, to guide the data gathering processes (and further the empirical analysis) this division was also adopted here to describe the various dimensions of NISs in a broad sense.

Finally, it has to be noted that the NISs approach has also raised several critical questions on its applicability and suitability for empirical studies as well as for policy-making (Raunio and Kautonen 2014). Notably, Miettinen (2002) has criticized the employment of the approach as a policy tool, Carlsson et al. (2002) have discussed the problems related to the delineation of innovation systems, since NISs do not develop in isolation but are influenced by other countries and their NISs (Davenport and Bibby 1999), and for example Intarakumnerd, Chairatana, and Tangchitpiboon (2002) have pinpointed some complications inherent in adopting such an approach in the context of developing countries. Additionally, the difficulties related to the empirical validation of the concept and crosscountry comparisons of NISs have been discussed in a range of studies (e.g. Balzat and Hanusch 2004; Guan and Chen 2012). However, despite this well-placed criticism the NISs approach can be considered as a valuable analytical tool for examining the issues of innovation and technological 
capabilities and catch-up due to its systemic nature that includes various "softer" dimensions, besides strict measures for innovation inputs and outputs, also relevant for economic development.

\subsection{Dimensions of the broad definition of national innovation systems}

A major factor in determining the innovative performance of a given country is the level and condition of its innovation and technological capabilities. These issues relate to the measurable items of research and development $(\mathrm{R} \& \mathrm{D})$ expenditure and personnel, scientific quality in terms of numbers of research articles, royalty and license fees as well as to patents. For example, the results of Furman and Hayes (2004, 1350) suggest that "continuously increasing investments in innovation is, ultimately, essential for achieving innovative leadership". However, innovation and technologic capabilities are essential but not sufficient to gather for the different aspects of innovation systems necessary for sustained innovation development. Rather, the NISs also need a certain degree of absorptive capacity for imitation-based technological development and catch-up (Castellacci and Natera 2013).

Thus, other dimensions besides innovation and technological capabilities are needed to explain the innovative performance of nations. One such dimension with almost a universal agreement on its positive impact for innovation is that of human capital (and education system). At the national level human capital is commonly proxied through various indicators depicting the official educational attainment levels of its population and other schooling related measures such as educational expenditures and teacher-pupil ratios (Gennaioli et al. 2013; Teixeira and Fortuna 2010). As stated above, empirical works have indeed corroborated the positive impacts of human capital (or educational attainment) on nations' innovative capabilities and performance (Makkonen and Inkinen 2013; Teles and Joiozo 2011). In fact, human capital can be seen as a major factor for countries in 
developing their NISs from a purely imitation-based phase towards a more developed innovation stage (Castellacci and Natera 2013).

Additionally, the quality of national infrastructures also matter. The dimension is commonly associated with indicators related to the knowledge transfer and diffusion aspects of NISs, including the numbers of Internet users and telephone subscribers (Baskaran and Muchie 2006) as well as the volume of cross-country transportation and the quality of national transport infrastructure also highly important for innovations (Ridley, Yee-Cheung, and Juma 2006). In particular, the importance of information and communication technologies (ICT) has been proven to play a significant role in the diffusion of knowledge across the globe, which is important for innovation creation as well as for the national absorptive capabilities in imitating and adopting innovations produced elsewhere (Castellacci and Natera 2013). This heightened importance of ICT, might turn out particularly problematic for developing countries, since according to empirical evidence, they seem to lack behind in the access to (and the ability to use) ICT (Hilbert 2010).

In turn, the economic competitiveness of nations has a pivotal role in the development of NISs. However, in the sense of the economic competitiveness discussed here, other factors than strict growth rates of gross domestic product (GDP) are taken into account as the dimension relates to the financial and legal aspects of NISs; in short, financial constraints significantly reduce the likelihood that firms have innovative activities (Savignac 2008). Thus, the importance of issues such as the time and cost of enforcing contracts, the availability of credits from the banking sector, and the importance of an open, free, and well-functioning financial system for the NIS development is evident (Castellacci and Natera 2011; Kim 2000).

In line, political and institutional factors are highly significant for vibrant NISs and technological catch-up (Mudombi and Muchie 2014; Pinto and Santos Pereira 2013). Therefore, countries with basic (democratic) freedoms (such as freedom of speech and press, political rights, etc.), low levels 
of corruption and institutions supportive towards innovation seem to do well in global NIS comparisons (Makkonen 2014), since political-institutional processes, stability, and arrangements play a crucial role in the competitive performance of firms at the sectoral and national levels (Kim 1998). For example, political instability exerts a strong (negative) influence on innovation inputs in NISs (Allard, Martinez, and Williams 2012) and efforts to foster innovations within an economy will be more productive if accompanied by policy reforms aimed at controlling corruption (Anokhin and Schulze 2009).

The last, but equally important, dimension of NISs covers the aspect of social capital. Social capital has been deemed as highly important for innovation creation in regional and national scales (Doh and Acs 2010; Kallio, Harmaakorpi, and Pihkala 2010) through its significance in forming trustworthy milieus for innovation cooperation (Kaasa 2009). However, the concept is both; fluid in its description (since there is no universally agreed definition of social capital) as well as hard to measure and validate (Tura and Harmaakorpi 2005). This renders any empirical treatment of the dimension as extremely difficult and subject to debate. Here, the concept is understood through the works of Putnam (2000) as the features of social organization (including networks, norms, and trust) that facilitate cooperation for mutual benefits. Accordingly, commonly utilized empirical proxies for social capital include measures related to mutual trust, associational activities and membership, importance of social ties, social equality (or inequality) as well as civic norms (Castellacci and Natera 2011; Doh and Acs 2010).

\subsection{Earlier empirical studies on technological catch-up}

The existing empirical evidence on technological catch-up seems to be rather inconsistent. For example, Furman and Hayes (2004) observed that the gap between the most and the least innovative countries (in terms of relative innovation productivity) had diminished during the twenty years' time- 
period they investigated. The gap still remained, but it was relatively smaller in 1999 than in the beginning of their observation period in 1978. Similarly, the list of countries to introduce innovations truly new-to-the-world had widened to include a number of former imitator countries. Contrary, Castellacci and Archibugi (2008) have presented evidence that whereas what they have termed as the "followers club" has come closer to the technological frontier, the marginalized group of countries has, in fact, experienced a widening gap in innovative capabilities vis-à-vis the rest of the world. Accordingly, Kemeny (2011) has shown that a large technology gap separates the most and the least sophisticated economies in the world. Moreover, according to his data and observation period from 1972 to 2001 this gap has been growing: the development of technological sophistication of economies was characterized by stagnation of countries at the bottom of the spectrum, moderate technological upgrading in the middle and rapid expansion of technology levels at the top.

When it comes to distinct country groupings it seems that for example the BRICS (Brazil, Russia, India, China, and South Africa) as well as the new EU-member countries of the East and Central Europe seem to have been able to catch-up to the world leaders in innovation (Altenburg, Schmitz, and Stamm 2008; Makkonen 2014). As pointed out in the introduction this, however, does not necessarily indicate that global convergence would be under way. Moreover, from a methodological point of view, recent studies on technological catch-up have noted that relying on a single metric related to world frontier innovation activities (such as the European Innovation Scoreboard) omits a number of important NIS factors (according to the broad definition) for follower countries and, hence, is inadequate for analysis concerning economies behind the technology frontier (Kravtsova and Radosevic 2012).

In sum, it seems that the evidence whether the gap between the most innovative and least innovative countries has indeed been diminishing over the last few decades is inconclusive. What is clearer is that at least some countries have been able to catch-up to the world leaders in innovation. 
Moreover, whether or not countries have been able to catch-up seems to depend much on their ability to develop their NISs (Fagerberg and Verspagen 2007). However, the existing studies do not convincingly indicate (or rather have not discussed the issue) global convergence in terms of the different dimensions of the broad definition of NISs since they 1) have more often focused on a restricted group of rich countries frequently neglecting the developing world and 2) have mainly focused on the innovative performance (narrow definition) of nations leaving aside the (broad definition) different dimensions of NISs (Castellacci and Archibugi 2008).

\section{Data and methods}

The data used here was gathered from the CANA database, which as stated by its constructors "provides full information for the whole set of country-year observations, i.e. it contains no missing values" (Castellacci and Natera 2013, 583). The database is comprised of 41 indicators (34 with full country coverage and seven for a smaller sample of countries) from the NIS related dimensions discussed above for 134 countries for a time period of 1980-2008. A thorough methodological description and statistical validation of the database can be found in Catellacci and Natera (2011). Suffice to say here, that the original missing values in the data (gathered from existing cross-country data sources of the World Bank, UNESCO, etc.) have been replaced with the best available estimates (calculated through the method of "multiple imputation") and that the database has an impressive array of variables compared to other available global databases (e.g. the ARCO database by Archigbugi and Coco [2004]). The indicators utilized here are presented in Table 1. The issue of convergence is discussed through standard descriptive statistics (quintiles and range) to produce a coherent picture whether or not the differences between the extremes (the highest and the lowest values) in NIS capabilities have been diminishing or widening between 1980 and 2008. 
$<$ Table 1 about here>

In terms of identifying the convergence clubs the method utilized here is that of principal component analysis (PCA). In short, PCA is a commonly applied method for constructing composite indexes i.e. when pursuing to compress the information present in several measures into one (or a few) principal components (PC) expressing the dimension under scrutiny (Jolliffe 2002). In PCA it is presupposed that there are statistically significant correlations between the variables included in the analysis. Therefore, the measures used in this study for PCA suitability are the Bartlett test of sphericity testing whether the values of the correlation matrix equals to zero and the Kaiser-Meyer-Olkin measure testing whether the partial correlation among variables is sufficiently high. The analyses conducted here passed these "suitability" tests.

The index scores, i.e. principal component scores (PCS), for individual countries are calculated in a way similar to regression analysis by weights determined on the basis of the analysis. Changes in PCS will reflect both the importance (loadings) of the various indicators included in the PC over time and shifts in countries' positions relative to each other (Fagerberg, Srholec, and Knell 2007). These PCS are standardized to a mean of zero, whereas the standard deviation of the distribution of PCS equals to one (DiStefano, Zhu, and Mîndrilâ 2009). By adopting the methodology used by Filippetti and Peyrache (2011) we can then define a Relative PCS Index (RPI) to describe the ratio between the PCS of a given observation unit i.e. country $(k)$ at a period of time $(t)$ in relation to the best performing country (Equation 1; bounded between one and zero):

$$
R P I_{k}^{t}=\frac{P C S_{k}^{t}}{P C S_{\max }^{t}}
$$


Thus, by repeating the analysis for every year one will be in a position to detect any clear groupings of convergence countries that (might) have been steadily increasing their capabilities in terms of NISs. The advantage here, when compared to composite indexes with fixed weights, is that the changes in the relative importance of the indicators included in the analysis is also taken into account. Thus, high performance in an indicator of a given country that has lost its explanatory power during the time period analysed does not lead to overestimations of the contemporary position of that country in the global ranking. Here the number of countries included was maximized, a direction highlighted by Filippetti and Peyrache (2011) as an important avenue for research, by excluding the variables of the CANA-database that did not have a full country coverage out of the PCA to address the phenomena of global convergence and catch-up with a wider set of countries (see Table 1).

\section{Results}

\subsection{Global convergence?}

When investigating the different dimensions of NISs (the index year was set to the start of the observation period: 1980) of the range between the minimum and maximum quintile cut off points, i.e. the gap between the best and the weakest performing countries in each indicator, it becomes obvious that a large scale global convergence is not underway (Figure 1). In the dimension of innovation and technological capabilities the gap has widened in every measured indicator. For royalty payments, patents, and $R \& D$ the widening of the gap is marked, but for scientific articles the divergent development paths have led to a staggering difference between the minimum and maximum quintiles, which was over four times higher in 2008 to what it was in 1980. When it comes to the dimension of human capital and education system; the evidence points towards widening gaps in terms of tertiary education as well as teacher-student ratios. The steep rise in the gap of tertiary education is in particular worrying for global convergence. However, as a distinct positive 
development the differences in primary and secondary education, mean-years-of-schooling, and public expenditure on education have narrowed down (a bit) during the observation period.

\section{$<$ Figure 1 about here>}

Contrary, in terms of the national infrastructures the situation seems bleak for global convergence. Whereas, the gap in indicators measuring paved roads has remained relatively stable, the gap has widened to that of the situation in 1980 in all the rest of the indicators. Access to the Internet, telephone subscribers, telecommunications revenue, departures of air carriers, and consumption of electricity point toward growing gaps of differing possibilities, where the developed nations enjoy positive growth patterns and the developing countries lag more and more behind. This is particularly evident in the case of access to the Internet, where in a short observation period the gap has widened thirty-six-fold in 2008 to that of the commercialization of the Internet in 1995. In the dimension of economic competiveness the situation has remained more or less unchanged, except for finance freedom where the gap has indeed narrowed down. In the other indicators, the gap has not widened, nor has it narrowed to a significant degree although fluctuating from year-to-year around the index score of one hundred and turning to a negative development, in terms of global convergence, in the very last years of the observation period.

However, as in the case of human capital, some positive signs can be found in the dimensions of political-institutional factors and social capital. The observed gaps in corruption, press freedoms, and Gini-coefficient were smaller in 2008 than in the start of the observation period. This development is, however, unstable as the range between the minimum and maximum quintiles seem to fluctuate heavily on a year-to-year basis. In the other measures of political and institutional factors and social capital (based on subjective indexes), the year-to-year changes in the range between the minimum 
and maximum values were arbitrary and, thus, omitted from Figure 1. To conclude: there are only weak signs of global convergence in some of the measures applied here in the dimensions of human and social capital as well as in political-institutional factors. As a whole, the country-wise differences in NIS capabilities, according to the individual indicators measured, seem to have either remained more or less the same or rather taken a turn towards growing differences between the best and the weakest performing countries.

\subsection{Convergence clubs}

A certain amount of catch-up can be detected from Figure 2: most countries in the lower end of the spectrum in 1980 seem to have grown the fastest when measured in PCS. Additionally, the statistically (highly) significant correlation coefficient of -0.307 between the (unbounded) PCS in 1980 and the experienced change (1980-2008) signal a presence of moderate convergence (cf. Filippetti and Peyrache 2011). However, the results still do not point towards a clear global convergence, due to the standardized nature of PCS. Furthermore, the countries at the top and bottom positions in the index have remained more or less the same (Appendix 1). Thus, in the following we are interested on the set of countries that have been able to steadily improve their capabilities in a balanced way.

$<$ Figure 2 about here $>$

When arranged according to the RPI scores and corresponding NIS rankings the countries form a clear cluster structure (Appendix 1). According to a hierarchical cluster analysis the two most obvious clusters (altogether four clusters plus one outlier, Gambia, were identified; including more clusters into the analysis did not change this initial solution to a significant degree) are formed for the leading 
countries (cluster number four) in the ranking and for the weakest performing countries (cluster number two). A third cluster (cluster number one) was formed from countries with mediocre RPI scores and NIS rankings. The interest here, however, lies in the countries that have been able to significantly improve their NIS capabilities: a clear group of converging countries was identified (Figure 3). This group (cluster number three) includes the Eastern European countries of Croatia, the Czech Republic, Estonia, Latvia, Lithuania, Romania, Slovakia, and Slovenia, the Latin American countries of Argentina, Chile, El Salvador, Honduras, Nicaragua, and Uruguay together with South Africa, South Korea, and (quite surprisingly) Mongolia. These countries have been able to steadily improve their capabilities in terms of the broader definition of NISs and now occupy positions right after the best performing countries. There are also other countries (for example Albania, Benin, Lesotho, Mali, and Oman) that have been able to catch-up significantly, but, however, were not identified as a part of the convergence cluster due to their lower RPI scores.

$<$ Figure 3 about here $>$

Accordingly, there are a number of countries that have lost their standings in the NIS rankings. These countries include some of the less developed countries of Africa, Asia, and Latin America, but surprisingly also the BRICS countries of China, India, and Russia (Appendix 1). It thus seems that, despite the earlier empirical evidence showing growth in terms of "hard" measures for innovation, China, India, and Russia did actually worse in 2008 than in 1980 when various "softer" politicalinstitutional factors are included into the analysis. This might not do justice to the countries in terms of their innovation output, but, however, still raises questions concerning the broader social sustainability of their reported growth and development. 


\subsection{Implications for economic development}

The discussion on NIS capabilities relate to their ability to produce innovations further transformed into economic development. By taking account the broader definition of NISs the paper has been able to raise some interesting points. First, the inclusion of a multitude of "soft" factors into the analysis does not change the composition of the top performing countries to a significant degree: the countries performing well here are the commonly identified innovation leaders of Nordic Countries together with the most developed nations of Europe and Northern America plus Japan. Second, however, many of the previously identified converging countries, when considering only hard factors of innovation, including some of the BRICS-countries (China, India, and Russia) have in fact lost their positions during the time period analysed here (Appendix 1), when compared through the lens of the broader definition of NISs. This leads to an important question: does the broader definition of NISs then have any relevance in terms of economic development of nations? When considering the global rankings in both NIS capabilities and GDP per capita in current US\$ (collected from the database of the World Bank) it seems evident that there is a positive association between economic development levels and performance in the NIS rankings (Figure 4). The statistically highly significant correlation coefficients of 0.756 for 1990 and 0.809 for 2008 corroborate this view.

$<$ Figure 4 about here $>$

However, there is no evident causality between changes from one ranking to another across the whole country set included: an improvement in one ranking does not automatically lead to an improvement in the other (Figure 5), not even for the countries that have been catching-up the most (i.e. the convergence club). Still one can see a definite correlation $(0.249 ; \mathrm{p}$-level $=0.004)$ between the changes in the NIS and economic development rankings: countries that have improved their 
performance in the NIS rankings are commonly those that have grown, in terms of GDP, the fastest. For example, when taking a closer look at the 17 countries of the group identified (Figure 3 ) as the convergence cluster, eleven have improved their performance in both rankings and four have experienced a standstill or (only) a modest drop in their standings in the GDP rankings. However, Argentina and South Africa, whose standings in the GDP rankings have plummeted despite the improvements in their standings in the NIS rankings, stand out as clear exceptions to this positive association. Accordingly, in the case of the other BRICS countries, whereas Brazil's and Russia's developments in both rankings are fairly similar (i.e. a standstill or a modest decline), India has improved its position in the GDP rankings despite its worsening standing in the NIS rankings. Finally, one of the most striking examples of the mismatch between the two rankings is offered by the case of China-a country that has done extremely well in enhancing its performance in terms of GDP irrespective of its less flattering RPI scores development.

$<$ Figure 5 about here $>$

In sum, NIS dynamics and economic development are definitely intertwined. Countries doing well in economic terms also excel in the NIS rankings and those who have improved their NIS capabilities are also commonly those that have grown in economic terms. This, however, does not imply a direct causality between the two (as the examples from BRICS countries illustrate). A significant improvement in the NIS scores and rankings is not (in many cases) mirrored as such in economic growth even after a time lag. One possible explanation to the non-causality that arises from the empirical analysis might be the existence of different dynamics between the socio-institutional and techno-economic subsystems (dimensions) of NISs. As discussed already by Perez (1983) the socioinstitutional factors may change at a different (country-specific) pace from the techno-economic 
factors, hampering the applicability of results produced by static methodologies (even if they are repeated over the whole period), but also showing that in order to develop in economic terms (only), a country does not necessarily need to improve its capabilities in all of the dimensions of NISs (as shown for example by the case of China). However, the development of the dimensions of the broader definition of NISs employed here have to be also seen through the lens of wider socio-institutional and socio-economic change of a given country together with improvements in the standard of living and basic freedoms of its citizens deemed important for development for example by the United Nations in its declaration of human rights.

\section{Conclusions}

Here, the concept of technological catch-up was explored through the NISs framework by including a wide array of indicators form the CANA database (from the years 1980-2008) to produce a coherent picture on the dynamics of global convergence and or divergence vis-á-vis the varying dimension of the broader definition of NISs. The most important research results can be summarizes as follows. First, according to the results, despite some positive signs in the dimensions of human capital, political institutional factors and social capital, in general, the global differences are growing i.e. the gaps between the best and the weakest performers are widening. Second, the analysis was able to indicate a clear group or a club of converging countries, including, as expected, many Eastern European and Latin American countries together with South Africa, and South Korea (plus Mongolia), that have consistently been catching-up to the top performers in NIS capabilities. What was surprising, in the light of the earlier literature, was that when "softer" political-institutional factors are included into the analysis China, India, and Russia seem actually to do worse in 2008 than in 1980. Third, the comparisons between NIS and economic growth rankings were not able to produce conclusive evidence on the interconnections between them. At first glance it seems that the two are 
definitely associated with each other since the NIS and economic development rankings are highly correlated. Then again, a further inspection does not indicate causality between the two: an improvement in one of the rankings does not always lead to a subsequent improvement in the other even after a time lag. However, it is also stressed here that the NIS development should not be only viewed as a means of gaining economic growth, but also as a measure for the broader sustainable and inclusive socio-economic development of the countries.

A definite policy implication of this study can therefore be found in an attempt to encourage countries to think beyond their economic growth rates when developing their respective NISs. NISs can be considered as more than merely the sum of innovation inputs and outputs and the following economic advancements. They can be viewed as the total value of the development in a given country including a broader set of "soft" dimensions such as basic political-institutional freedoms as well as the qualities of national infrastructures and educational system together with the "hard" measures of economic and innovative success. Striving to develop the economy in a way that takes into account both the "hard" and the "soft" factors ought to be universally embraced as a cornerstone to witch economic growth should be based on. With this it is also acknowledged that the western ways and ideals are not the only ones than have a change of success. Rather, future work could turn its attention to different descriptions of NISs, those that have not been drawn from the perspective of best performing benchmarks of western countries, but on the viewpoint of less successful development countries. The changes of duplicating the results from well-performing countries in all parts of the globe are slim. Thus, it is evident that there is a lot to learn from all spectrums of global players: those who are already doing well, those who are catching-up to the world leaders, and those who have stayed behind and marginalized. Not just showing with successful examples what should be done, but also discussing with less successful cases what has not worked, would benefit the contemporary discussion on global convergence and technological catch-up. 
Finally, it has to be noted that the discussion on the broader definition of NISs together with the chosen methodology is not without its limitations. First, the concept of NISs itself has received its fair share of criticism. However, as shown here the approach can serve its purpose as an analytical tool, when keeping in mind the varying problems related to its empirical treatment and validation. Second, it is acknowledged here that PCA is a rather descriptive method: while useful for exploring the data and in deriving a "big picture" further analysis with more sophisticated methodology are needed to analyse the issues brought forth here in a greater detail. For example, an interesting further step would be to test the efficiency of the NISs as in Zabala-Iturriagagoitia et al. (2007), to divide the dimensions of NISs into separate socio-institutional and techno-economic sub-systems (or pillars) as in Hanusch and Pyka (2007) or to check for the compositional effects of NISs as in Filippetti and Peyrache (2011) to get a better picture of the interconnectedness of the broader definition of NISs (and its various dimensions or sub-systems) and economic growth. Third, despite its usefulness the database utilized here has its limitations, as it has been compiled from many subjective evaluations (i.e. indicators based on expert opinions) and as it omits a number of important indicators, essential when discussing the innovative performance of nations. Thus, the inclusion of a wider set of objective measures of development and innovation input variables (such as R\&D expenditures) for a wider set of countries could produce interesting further insights into the dynamics of NISs.

\section{Acknowledgements}

I am grateful to the anonymous reviewers and to the discussants of the session chaired by professor Andreas P. Cornett at the $17^{\text {th }}$ Uddevalla Symposium (held in Uddevalla, Sweden, in June 2014), where an earlier version of this paper was presented, for their comments on improving the paper. 


\section{References}

Abramovitz, M. 1986. “Catching Up, Forging Ahead, and Falling Behind.” Journal of Economic History 46 (2): $385-$ 406.

Allard, G., C. Martinez, and C. Williams. 2012. "Political Instability, Pro-Business Market Reforms and Their Impacts on National Systems of Innovation.” Research Policy 41 (3): 638-651. doi:10.1016/j.respol.2011.12.005.

Altenburg, T., H. Schmitz, and A. Stamm. 2008. "Breakthrough? China's and India's Transition from Production to Innovation.” World Development 36 (2): 325-344. doi:10.1016/j.worlddev.2007.06.011.

Anokhin, S., and W. Schulze. 2009. "Entrepreneurship, Innovation, and Corruption.” Journal of Business Venturing 24 (5): 465-476. doi:10.1016/j.jbusvent.2008.06.001.

Archibugi, D., and A. Coco. 2004. “A New Indicator of Technological Capabilities for Developed and Developing Countries (ARCO).” World Development 32 (4): 629-654. doi:10.1016/j.worlddev.2003.10.008.

Balzat, M., and H. Hanusch. 2004. "Recent Trends in the Research on National Innovation Systems." Journal of Evolutionary Economics 14 (2): 197-210. doi:10.1007/s00191-004-0187-y.

Baskaran, A., and M. Muchie., eds. 2006. Bridging the Digital Divide. London: Adonis \& Abbey.

Carlsson, B., S. Jacobsson, M. Holmén, and A. Rickne. 2002. "Innovation Systems: Analytical and Methodological Issues.” Research Policy 31 (2): 233-245. doi:10.1016/S0048-7333(01)00138-X.

Castellacci, F., and D. Archibugi. 2008. "The Technology Clubs: The Distribution of Knowledge across Nations." Research Policy 37 (10): 1659-1673. doi:10.1016/j.respol.2008.08.006.

Castellacci, F., and J. M. Natera. 2011. "A New Panel Dataset for Cross-Country Analyses of National Systems, Development and Growth (CANA)." Innovation and Development $1 \quad$ (2): $205-226$. doi:10.1080/2157930X.2011.605871.

Castellacci, F., and J. M. Natera. 2013. "The Dynamics of National Innovation Systems: A Panel Cointegration Analysis of the Coevolution between Innovative Capability and Absorptive Capacity." Research Policy 42 (3): $579-594$. doi:10.1016/j.respol.2012.10.006.

Davenport, S., and D. Bibby 1999. "Rethinking a National Innovation System: The Small Country as 'SME'.” Technology Analysis \& Strategic Management 11 (3): 431-462. doi:10.1080/095373299107447.

DiStefano, C., M. Zhu, and D. Mîndrilâ. 2009. "Understanding and Using Factor Scores: Considerations for the Applied Researcher.” Practical Assessment, Research \& Evaluation 14 (20), 1-11. 
Doh, F., and Z. Acs 2010. “Innovation and Social Capital: A Cross-Country Investigation.” Industry and Innovation 17 (3): 241-262. doi:10.1080/13662711003790569.

Fagerberg, J., and M. Godinho 2004. "Innovation and Catching-Up.” In The Oxford Handbook of Innovation, edited by J. Fagerberg, D. Mowery, and R. Nelson, 514-544. Oxford: Oxford University Press.

Fagerberg, J., and K. Sapprasert. 2011. "National Innovation Systems: The Emergence of a New Approach.” Science and Public Policy 38 (9): 669-679. doi:10.3152/030234211X13070021633369.

Fagerberg, J., and M. Srholec. 2008. "National Innovation Systems, Capabilities and Economic Development.” Research Policy 37 (9): 1417-1435. doi:10.1016/j.respol.2008.06.003.

Fagerberg, J., M., Srholec, and M. Knell. 2007. “The Competitiveness of Nations: Why Some Countries Prosper While Others Fall Behind?” World Development 35 (10): 1595-1620. doi:10.1016/j.worlddev.2007.01.004.

Fagerberg, J., and B. Verspagen. 2007. "Innovation, Growth and Economic Development: Have the Conditions for CatchUp Changed?” International Journal of Technological Learning, Innovation and Development 1 (1), 13-33.

Filippetti, A., and A. Peyrache. 2011. "The Patterns of Technological Capabilities of Countries: A Dual Approach Using Composite Indicators and Data Envelopment Analysis.” World Development 39 (7): 1108-1121. doi:10.1016/j.worlddev.2010.12.009.

Freeman, C. 1987. Technology Policy and Economic Performance. London: Pinter.

Freeman, C. 2002. "Continental, National and Sub-National Innovation Systems: Complementarity and Economic Growth.” Research Policy 31 (2): 191-211. doi:10.1016/S0048-7333(01)00136-6.

Furman, J., and R. Hayes. 2004. "Catching Up or Standing Still? National Innovative Productivity among 'Follower' Countries, 1978-1999.” Research Policy 33 (9): 1329-1354. doi:10.1016/j.respol.2004.09.006.

Gennaioli, N., R. La Porta, F. Lopez-de-Silanes, and A. Shleifer. 2013. "Human Capital and Regional Development." Quarterly Journal of Economics 128 (1): 105-164. doi:10.1093/qje/qjs050.

Gerschenkron, A. 1962. Economic Backwardness in Historical Perspective. Cambridge: Belknap Press.

Guan, J., and K. Chen. 2012. "Modeling the Relative Efficiency of National Innovation Systems.” Research Policy 41 (1): 102-115. doi:10.1016/j.respol.2011.07.001.

Hanusch, H., and A. Pyka. 2007. “Applying a Comprehensive Neo-Schumpeterian Approach to Europe and Its Lisbon Agenda.” In 50 Years of EU Economic Dynamics, edited by R. Tilly, P. Welfens, and M. Heise, 275-299. Berlin: Springer-Verlag. 
Hilbert, M. 2010. "When Is Cheap, Cheap Enough to Bridge the Digital Divide? Modeling Income Related Structural Challenges for Technology Diffusion in Latin America." World Development 38 (5): 756-770. doi:10.1016/j.worlddev.2009.11.019.

Intarakumnerd, P., P. Chairatana, and T. Tangchitpiboon. 2002. "National Innovation System in Less Successful Developing Countries: The Case of Thailand." Research Policy 31 (8-9): 1445-1457. doi:10.1016/S00487333(02)00074-4.

Jolliffe, I. 2002. Principal Component Analysis. New York: Springer.

Kaasa, A. 2009. "Effects of Different Dimensions of Social Capital on Innovative Activity: Evidence from Europe at the Regional Level.” Technovation 29 (3): 218-233. doi:10.1016/j.technovation.2008.01.003.

Kallio, A., V. Harmaakorpi, and T. Pihkala. 2010. “Absorptive Capacity and Social Capital in Regional Innovation Systems: The Case of the Lahti Region in Finland." Urban Studies 47 (2): 303-319. doi:10.1177/0042098009346373.

Katz, J. 2006. "Indicators for Complex Innovation Systems." Research Policy 35 (7): 893-909. doi:10.1016/j.respol.2006.03.007.

Kemeny, T. 2011. "Are International Technology Gaps Growing or Shrinking in the Age of Globalization?” Journal of Economic Geography 11 (1): 1-35. doi:10.1093/jeg/lbp062.

Kim, L. 2000. “Korea’s National Innovation System in Transition.” In Technology, Learning, and Innovation, edited by L. Kim, and R. Nelson, 335-360. Cambridge: Cambridge University Press.

Kim, S. 1998. “The Korean System of Innovation and the Semiconductor Industry: A Governance Perspective.” Industrial and Corporate Change 7 (2): 275-309. doi:10.1093/icc/7.2.275.

Kravtsova, V., and S. Radosevic 2012. “Are Systems of Innovation in Eastern Europe Efficient?” Economic Systems 36 (1): 109-126. doi:10.1016/j.ecosys.2011.04.005.

Lundvall, B-Å., ed. 1992. National Systems of Innovation. London: Pinter.

Lundvall, B-Å. 2011. "Notes on Innovation Systems and Economic Development.” Innovation and Development 1 (1): 25-38. doi:10.1080/2157930X.2010.551064.

Makkonen, T. 2014. "National Innovation System Dynamics in East Central Europe, the Baltic Countries and Russia." In Geo-Regional Competitiveness in Central and Eastern Europe, the Baltic Countries, and Russia, edited by A. Zhuplev, and K. Liuhto, 32-56. Hershey: IGI Global. 
Makkonen, T., and T. Inkinen. 2013. "Innovative Capacity, Educational Attainment and Economic Development in the European Union: Causal Relations and Geographical Variations.” European Planning Studies 21 (12): $1958-1976$. doi:10.1080/09654313.2012.722968.

Miettinen, R. 2002. National Innovation System - Scientific Concept or Political Rhetoric. Helsinki: Edita.

Mudombi, S., and M. Muchie. 2014. “An Institutional Perspective to Challenges Undermining Innovation Activities in Africa.” Innovation and Development 4 (2): 313-326. doi:10.1080/2157930X.2014.921272.

Nelson, R., ed. 1993. National Innovation Systems. Oxford: Oxford University Press.

Nelson, R. 2004. "The Challenge of Building an Effective Innovation System for Catch-Up.” Oxford Development Studies 32 (3): 365-374. doi:10.1080/1360081042000260575.

Perez, C. 1983. "Structural Change and Assimilation of New Technologies in the Economic and Social Systems.” Futures 15 (5): 357-375. doi:10.1016/0016-3287(83)90050-2.

Pinto, H., and T. Santos Pereira. 2013. "Efficiency of Innovation Systems in Europe: An Institutional Approach to the Diversity of National Profiles.” European Planning Studies 21 (6), 755-779. doi:10.1080/09654313.2012.665033.

Putnam, R. 2000. Bowling Alone. New York: Simon \& Schuster.

Raunio, M., and M. Kautonen. 2014. “Transnationalizing Innovation Systems by Transplanting Innovation Platforms.” Innovation and Development 4 (1), 145-160. doi:10.1080/2157930X.2013.876804.

Ridley, T., L. Yee-Cheong, and C. Juma. 2006. "Infrastructure, Innovation and Development.” International Journal of Technology and Globalisation 2 (3-4): 268-278.

Savignac, F. 2008. "Impact of Financial Constraints on Innovation: What Can Be Learned from a Direct Measure?" Economics of Innovation and New Technology 17 (6): 553-569. doi:10.1080/10438590701538432.

Teixeira, A., and N. Fortuna. 2010. "Human Capital, R\&D, Trade and Long-Run Productivity: Testing the Technological Absorption Hypothesis for the Portuguese Economy, 1960-2001." Research Policy 39 (3): 335-350. doi:10.1016/j.respol.2010.01.009.

Teles, V., and R. Joiozo. 2011. "Human Capital and Innovation: Evidence from Panel Cointegration Tests.” Applied Economics Letters 18 (17): 1629-1632. doi:10.1080/13504851.2011.556584.

Tura, T., and V. Harmaakorpi. 2005. "Social Capital in Building Regional Innovative Capability.” Regional Studies 39 (8): 1111-1125. doi:10.1080/00343400500328255.

Zabala-Iturriagagoitia, J., P. Voigt, A. Gutiérrez-Gracia, and F. Jiménez-Sáez. 2007. "Regional Innovation Systems: How to Assess Performance.” Regional Studies 41 (5): 661-672. doi:10.1080/00343400601120270. 


\section{Appendix 1. NIS rankings}

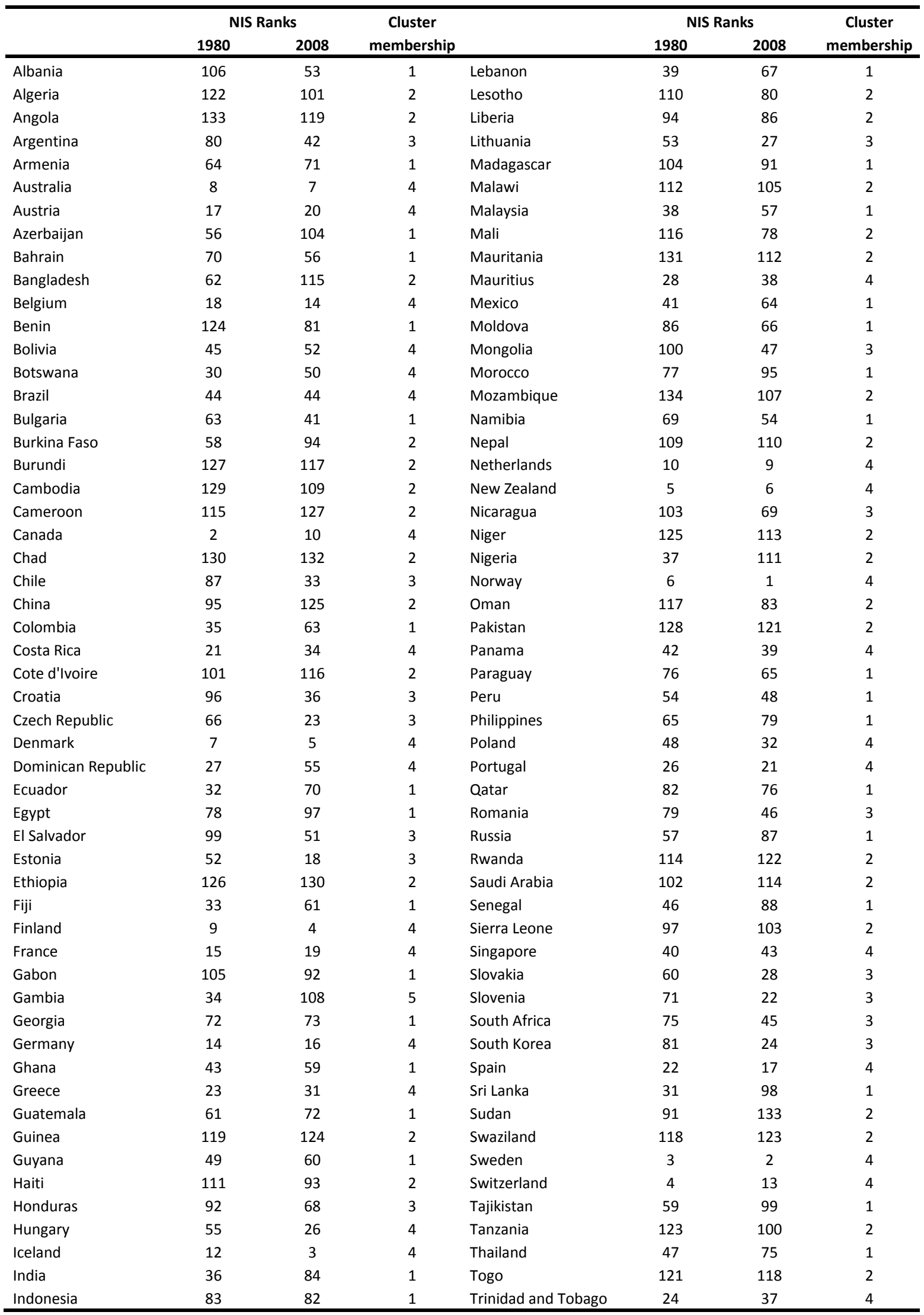




\section{Continued}

\begin{tabular}{|c|c|c|c|c|c|c|c|}
\hline Iran & 107 & 128 & 2 & Tunisia & 93 & 102 & 1 \\
\hline Ireland & 19 & 11 & 4 & Turkey & 50 & 58 & 1 \\
\hline Israel & 13 & 29 & 4 & Uganda & 108 & 106 & 2 \\
\hline Italy & 20 & 25 & 4 & Ukraine & 51 & 49 & 1 \\
\hline Jamaica & 29 & 40 & 4 & United Kingdom & 11 & 12 & 4 \\
\hline Japan & 16 & 15 & 4 & United States & 1 & 8 & 4 \\
\hline Jordan & 98 & 89 & 1 & Uruguay & 90 & 35 & 3 \\
\hline Kazakhstan & 74 & 85 & 1 & Uzbekistan & 89 & 129 & 2 \\
\hline Kenya & 85 & 96 & 2 & Venezuela & 25 & 77 & 1 \\
\hline Kuwait & 68 & 62 & 1 & Vietnam & 113 & 120 & 2 \\
\hline Kyrgyzstan & 67 & 74 & 1 & Yemen & 132 & 126 & 2 \\
\hline Lao PDR & 120 & 131 & 2 & Zambia & 88 & 90 & 1 \\
\hline Latvia & 84 & 30 & 3 & Zimbabwe & 73 & 134 & 2 \\
\hline
\end{tabular}


Table 1. The indicators of the CANA-database (for a more detailed list and original data sources see

\section{Castellacci and Natera [2011]).}

\begin{tabular}{|c|c|c|}
\hline Dimension / Indicator & Short & $\begin{array}{c}\text { Countries } \\
\text { included in CANA }\end{array}$ \\
\hline \multicolumn{3}{|l|}{ Innovation and technological capabilities } \\
\hline Royalty and license fees per capita & Royalty & 134 \\
\hline US Patents granted per inhabitant & Patents & 134 \\
\hline Scientific and technical journal articles per million inhabitants & Articles & 134 \\
\hline R\&D expenditure as \% of GDP * & $R \& D$ & 94 \\
\hline \multicolumn{3}{|l|}{ Education system and human capital } \\
\hline Primary enrolment ratio & Primary & 134 \\
\hline Secondary enrolment ratio & Secondary & 134 \\
\hline Tertiary enrolment ratio & Tertiary & 134 \\
\hline Mean years of schooling & Schooling & 134 \\
\hline Public expenditure on education & Public & 134 \\
\hline Primary pupil-teacher ratio & Teacher & 134 \\
\hline \multicolumn{3}{|l|}{ Infrastructures } \\
\hline Telecommunications revenue as $\%$ of GDP & Telecom & 134 \\
\hline Electric power consumption & Electric & 134 \\
\hline Internet users per 1000 inhabitants (since 1995) & Internet & 134 \\
\hline Fixed-line plus mobile telephone subscribers per 1000 inhabitants & Telephone & 134 \\
\hline Paver roads as $\%$ of total roads & Roads & 134 \\
\hline Departures of air carriers registered in the country per 1000 inhabitants & Departures & 134 \\
\hline \multicolumn{3}{|l|}{ Economic competitiveness } \\
\hline Enforcing contracts: Time & Enforce T & 134 \\
\hline Enforcing contracts: Cost & Enforce C & 134 \\
\hline Domestic credit by banking sector as \% of GDP & Credit & 134 \\
\hline Finance freedom (assessment) & Finance & 134 \\
\hline Openness indicator [(Import + Export)/GDP] & Openness & 134 \\
\hline \multicolumn{3}{|l|}{ Political-institutional factors } \\
\hline Corruption perception index & Corruption & 134 \\
\hline Freedom of press index (print, broadcast, and internet freedom) & Press I & 134 \\
\hline Freedom of press index (journalist freedom) & Press II & 134 \\
\hline Extent of freedom of speech & Speech & 134 \\
\hline Index of physical integrity and human rights & Human R & 134 \\
\hline Index of women's rights & Women's R & 134 \\
\hline Index of political rights & Political R & 134 \\
\hline Civil liberties (basic freedoms) & Liberties & 134 \\
\hline Extent of freedom of association & Association & 134 \\
\hline Electoral self-determination (freedom of political choice) & Self-D & 134 \\
\hline Index of democracy and autocracy & Democracy & 134 \\
\hline Index of the intensity of armed conflicts & Conflicts & 134 \\
\hline Index of legislative electoral competitiveness & Legislative & 134 \\
\hline Index of executive (branches in government) electoral competitiveness & Executive & 134 \\
\hline \multicolumn{3}{|l|}{ Social capital * } \\
\hline Importance of friends (index) & Friends & 80 \\
\hline Importance of family (index) & Family & 80 \\
\hline Importance of marriage (survey measure) & Marriage & 80 \\
\hline Gini index & Gini & 80 \\
\hline Social trust (survey measure) & Trust & 80 \\
\hline Happiness (index) & Happiness & 80 \\
\hline
\end{tabular}

\footnotetext{
* Excluded from PCA
} 


\section{Figure captions}

Figure 1. The relative change in the range (maximum-minimum quintile cut off points) of different dimensions and indicators of NIS (notice the varying scales; for Internet users the index year was set to 1995; $\mathrm{N}=134$ countries, except $\mathrm{N}=94$ for $\mathrm{R} \& \mathrm{D}$ and $\mathrm{N}=80$ for Gini-coefficient).

Figure 2. Convergence in the NIS capabilities in the observation period of 1980-2008 according to the unbounded principal component scores ( $\mathrm{N}=134$ countries).

Figure 3. The convergence club as identified by hierarchical cluster analysis.

Figure 4. NIS and economic development (in terms of GDP per capita) rankings in 1990 and 2008.

Figure 5. The changes in NIS and economic development (in terms of GDP per capita) rankings 1990-2008. 

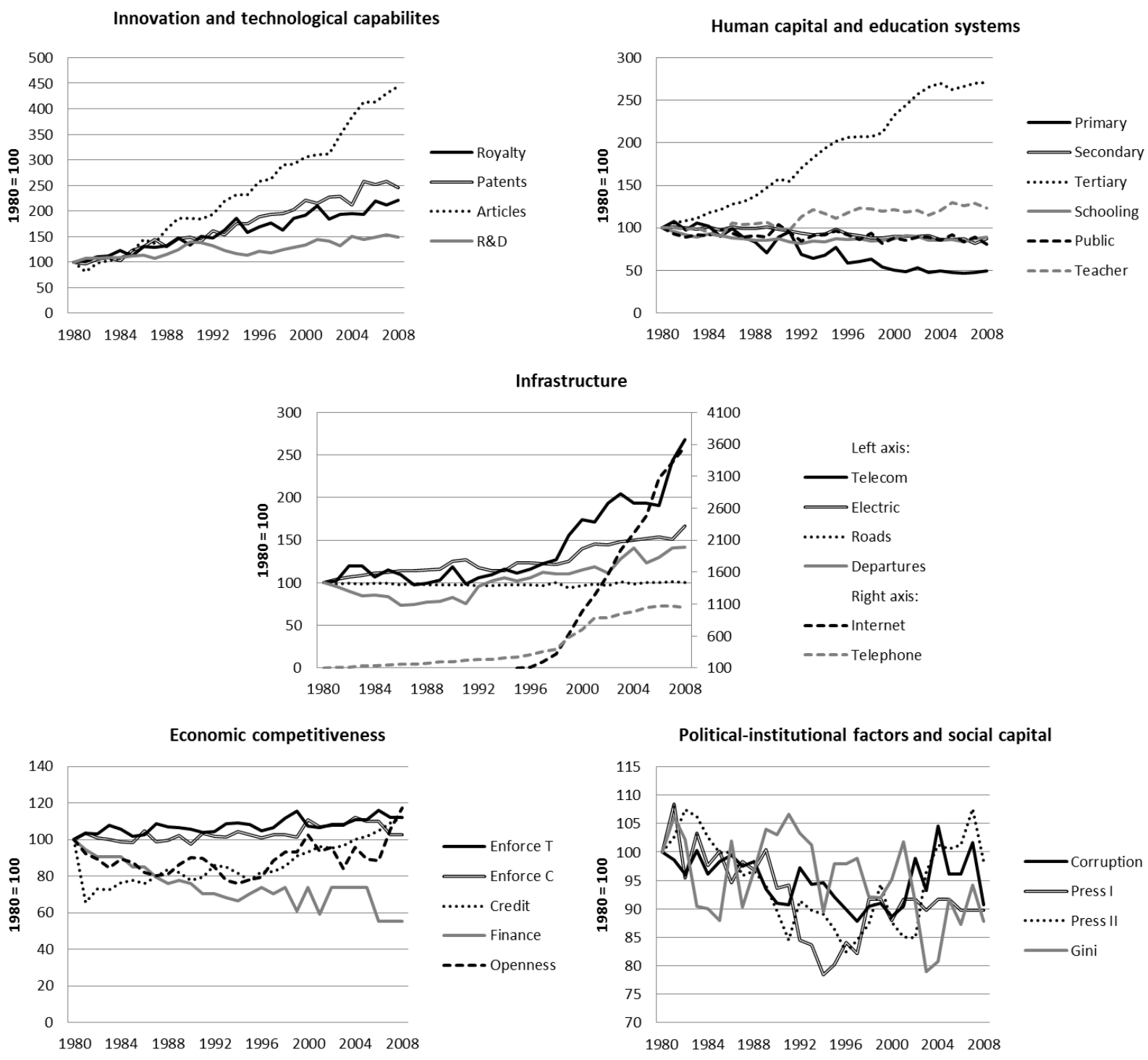

Figure 1.

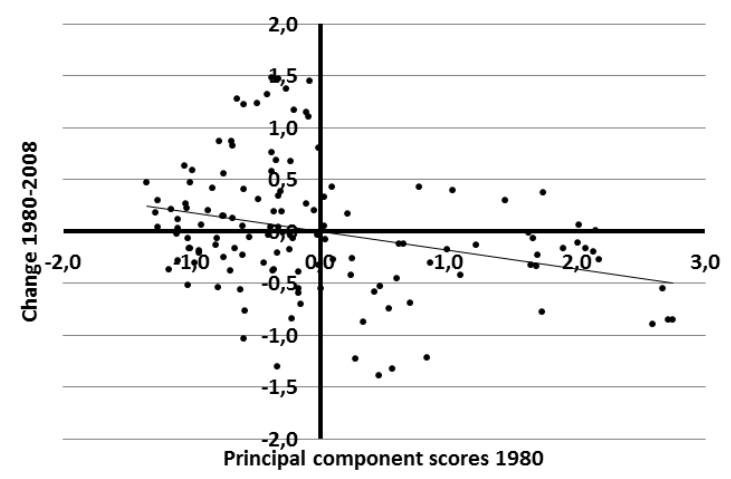

Figure 2. 


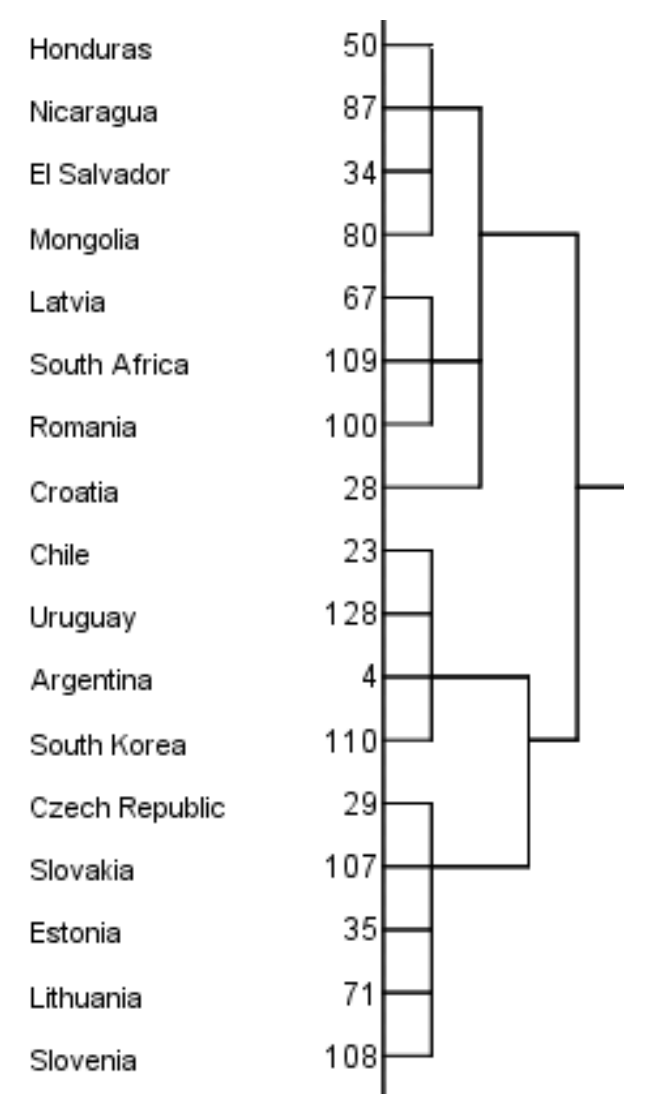

Figure 3.

1990

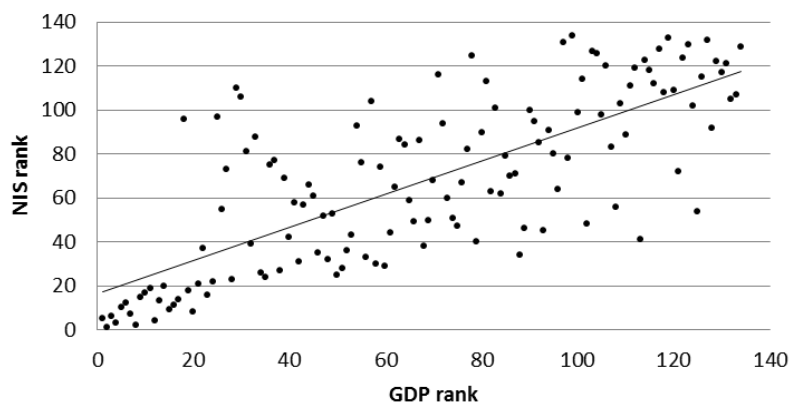

2008

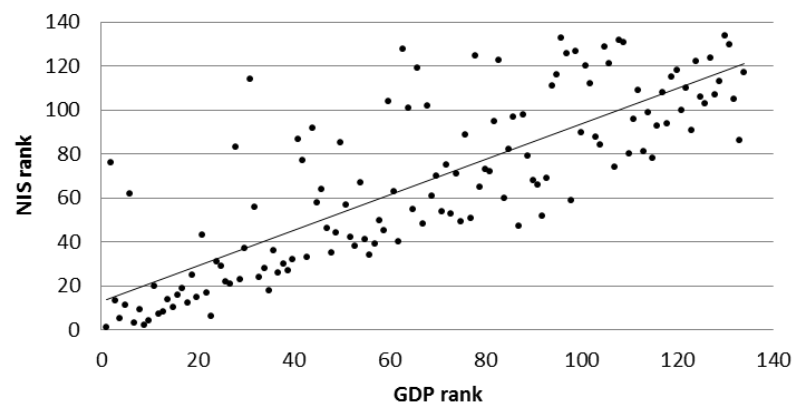

Figure 4. 


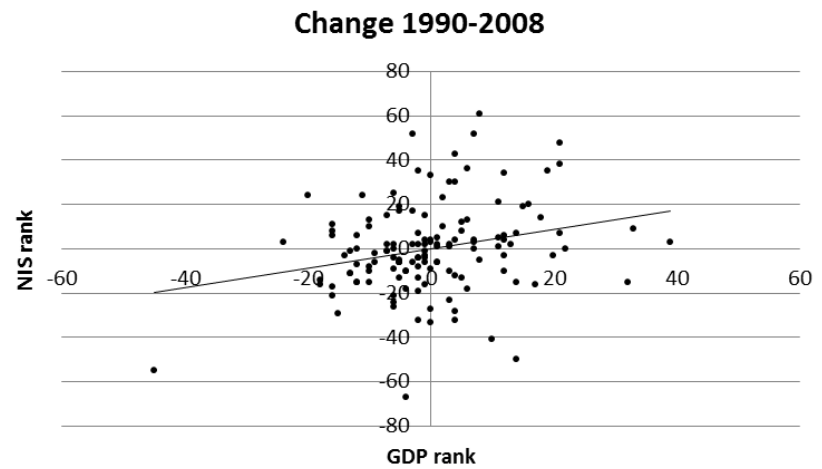

Figure 5. 